\title{
Review on Corrosion in Solar Panels
}

\author{
Abd Allah S. A. El-Gharabawy \\ The Egyptian Ethylene \& Derivatives Company - ETHYDCO, Alexandria, Egypt
}

Corresponding Author; Second Author, Postal address, Tel: +90 312123 4567,

Fax: $+20(3) 2020338$

aelgharbawy@ethydco-eg.com

Received: 13.12.2018 Accepted:28.12.2018

\begin{abstract}
Fossil fuels are not renewable energy in addition they create massive pollution in the environment. This pollution affects air, water and the food. Because of global fossil fuel shortage and environmental pollution, solar energy utilization has developed rapidly. Solar energy is considered the energy supplied by the sun that is a renewable and clean energy. This review investigates corrosion of silver, corrosion of solar cells and ways of control corrosion process of solar cell.
\end{abstract}

Keywords corrosion, solar panel, corrosion control.

\section{Introduction}

Silver is the crucial and vital ingredient in the photovoltaic cells, which absorb the rays of the sun; therefore convert into energy. Silver paste is used in about Ninety percent of crystalline silicon photovoltaic cells. Corrosion is simply the deterioration of a metal because of chemical reactions between it and the surrounding environment. Corrosion converts a refined metal to a more chemically stable form, such as its oxide, hydroxide, or sulfide. Formation of iron oxides is called rusting, it is a known example of electrochemical corrosion. Corrosion can be controlled via many selections. Choosing of corrosion control depends on safety condition, cost, ease of applications as well as the technical assumptions.

\section{Silver corrosion}

Silver is a noble metal so it has a high ability to resist corrosion. Moisture is most famous factor that cause corrosion as water provide the environment to absorb atmospheric gases.

Corrosion in solar panel occurs in wire that made of sliver. Atmosphere contains moisture, oxygen, carbonate and sulfate causes corrosion in silver wire and silver compound is formed by some chemical attack [1].

Carbon dioxide in atmospheric environment is abundant and it will react with aqueous surface layers of silver so a weak acid will be formed.
Bromine, Iodine or chlorine may attack silver, so a solid product of aqueous ionic complex $\mathrm{AgCl}$ will appeare.

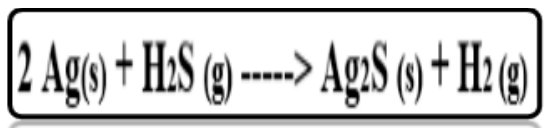

Silver reaction with atmospheric sulfur

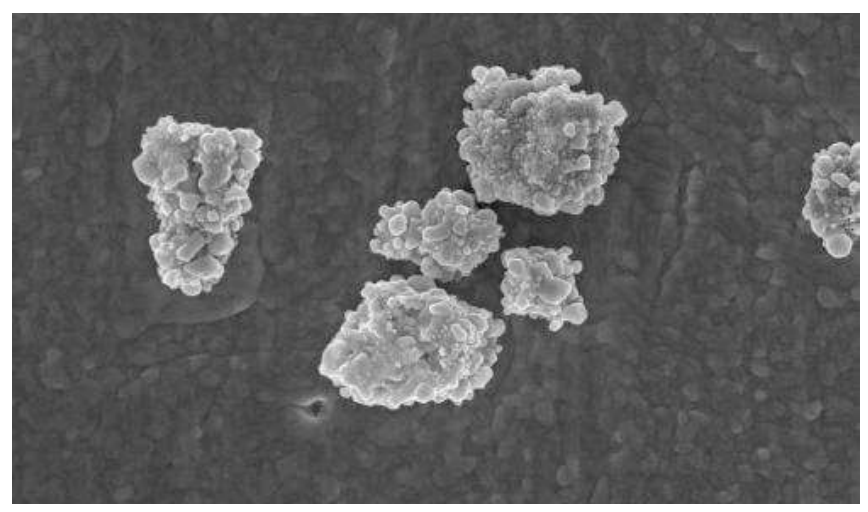

Fig 1: Scanning electron microscope (SEM) revealed clusters of metallic silver and silver chloride compound [3] 
INTERNATIONAL JOURNAL OF SMART GRID

Abd Allah S. A. El-Gharabawy, Vol.2, No.4, December, 2018

\section{Silver Corrosion Control}

Many preventative steps can conserve silver from corrosion such as [4]:

- Prevent greases and salts from touching polished surface of cells.

- Keep silver away from environments that has high sulfur content as sulfur react with silver and form black sulfide.

- Preserve silver in a dry ventilated area to keep away from water, sulfur, carbon dioxide and harmful elements.

- Keep silver always clean from dust as dust absorb water in atmosphere then corrodes metal.

- Using harsh chemicals is prevented as it damage silver and may form another layer of metal on silver.

\section{Corrosion Process in Photovoltaic}

Creation of voltage or electric current in a material once it exposed to light is called the photovoltaic effect. Light excites the transfer of electrons into higher energy band so electron is considered a charge carriers for electric current [7].

A thin film photovoltaic module has transparent electrodes on front and back surfaces of a semi conductive layer. Both transparent electrodes pass light to the semi conductive layer for photovoltaic purposes as shown in Fig 2.

Corrosion occurs firstly on the edge of photovoltaic module owing to presence of moisture and its reaction with sodium that exisits in the cover glass as shown in figures 3,4.The corrosion of glass cover or Transparent Conductive Oxide (TCO) cannot be fixed and leads to continuous power losses [2]. The result of this action will make TCO milky and loses its conducting properties and consequently, the photovoltaic module efficiency will lessen.

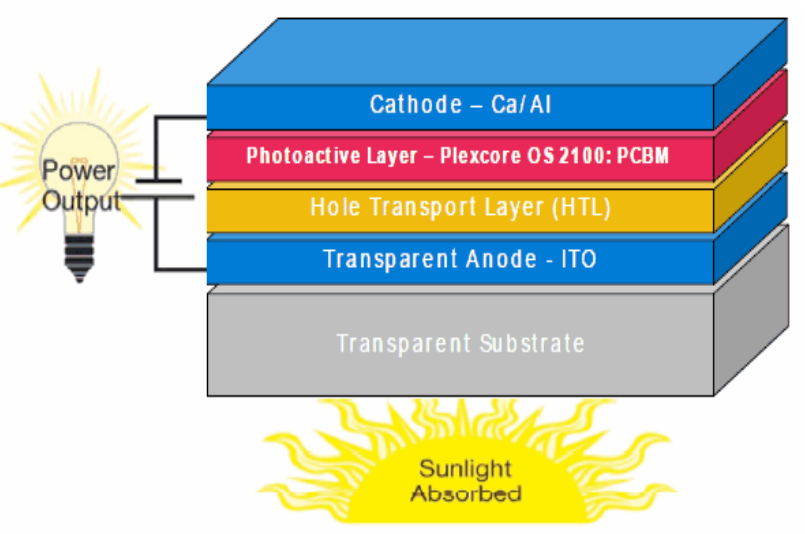

Fig 2: Photovoltaic layers

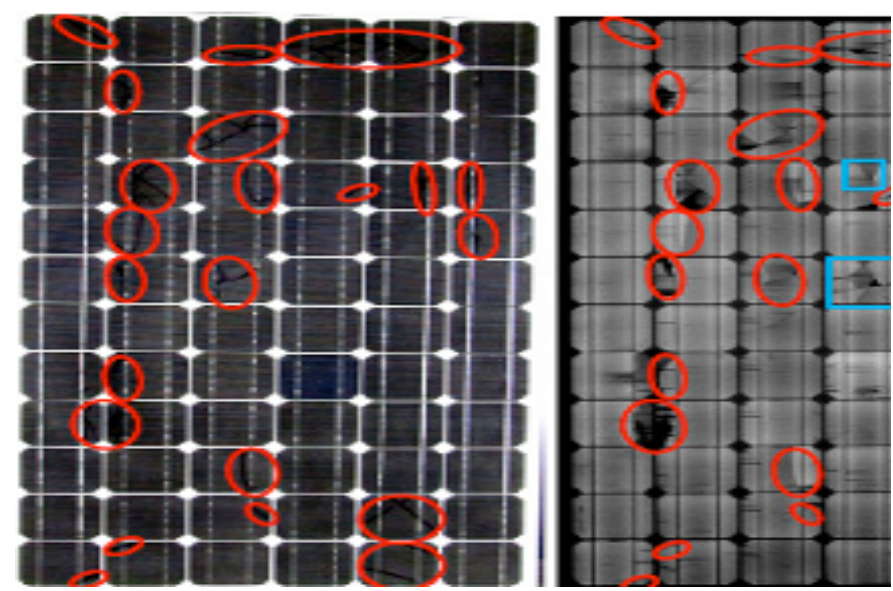

Fig 3: Corrosion within solar panels due to cracks

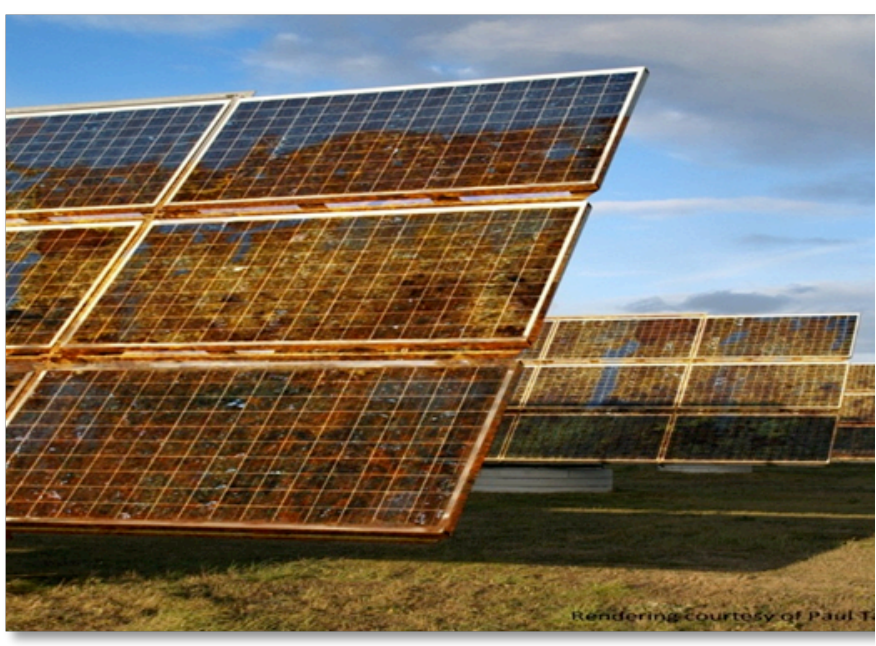

Fig 4: Corrosion in solar cell due to an electrochemical processes

\section{Corrosion Control}

Corrosion can be controlled in several ways:

- Coatings: it is considered the most important tool for corrosion resistance.

- Corrosion inhibitors: they are materials that reduce corrosion rate of certain environment once they are placed in that certain environment.

- Selection of materials: Stainless steel, plastics, special alloys have a high resistance to corrosion so utilizing of these materials will improve the lifespan of structures.

\section{Corrosion Control of photovoltaic}

Corrosion control of photovoltaic will be applied by elimination corrosion for inner parts and outer frame. The following methods are used:

\section{- Polymeric Packaging}

- Stainless Steel Frame. 
raised up and consequently, It does not need complicated and expensive equipment. [8]

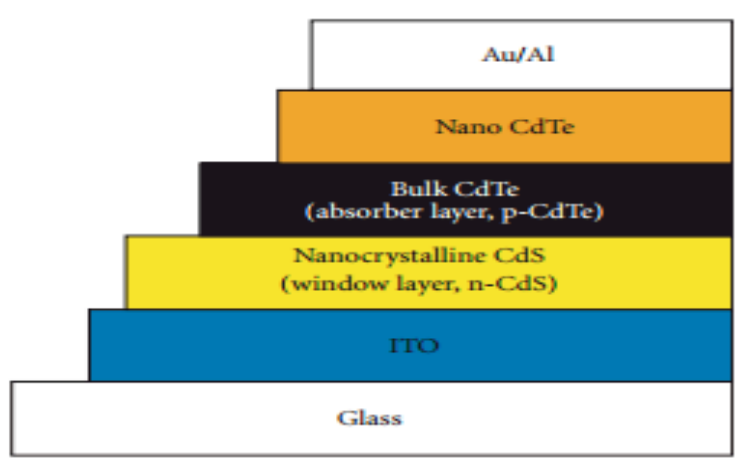

Fig 6: Nano coating of solar panel

\section{Conclusion}

In this paper, the application of corrosion control of solar panels is illustrated. The most important ways are polymer packaging, stainless steel frame and coating. Each of the previous stated method are widely used in industrial solar panels as well as performing the required function effectively.

\section{References}

\section{Stainless Steel Frame}

Stainless steel is choose to be used in photovoltaic cell due to high resistance of corrosion so it is used as a frame for panel. Although Stainless steel is expensive, it does not need any additional corrosion control steps such as coating or corrosion inhibitors [6].

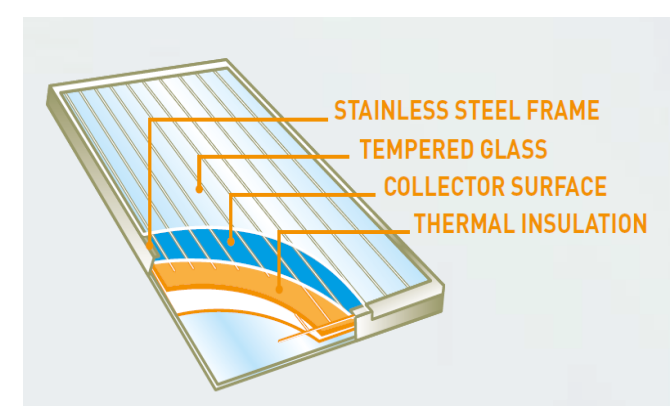

Fig 5: Stainless steel frame

\section{Nano-Coating Processes in Solar Energy Systems}

Incorporation of nano into solar panel can not only enhance the mechanical properties of the polymers but it also endows polymers with some other functional capabilities, such as antibacterial activity

Cadmium telluride (CdTe) photovoltaics is the common nano material in panel industry due to the high activity to absorb and convert sunlight into electricity.In addition that, it has a high resistivity against water vapor and corrosive gases.

The advantage of this process is that the transport way for the excited charge carriers in the absorber is decreased dramatically. The optical way for photon absorption is
[1] R. B. Leighou, Chemistry of Engineering Materials (New York: McGraw-Hill, 1942). pp 164-174.

[2] D. E. Carlson, R. Romero , F. Willing, D. Meakin , L. Gonzalez , R. Murphy, H. R. Moutinho and M. AlJassim, Corrosion Effects in Thin-Film Photovoltaic Modules, PROGRESS IN PHOTOVOLTAICS: RESEARCH AND APPLICATIONS Prog. Photovolt: Res. Appl. 2003; 11:377-386.

[3] INFORMS website, March 2017: https://phys.org/news/2013-12-corrosion-silver-cluesatmospheric-conditions.html

[4] INFORMS website, March 2017: corrosion

[5] Ethylene-Vinyl Acetate Potential Problems for Photovoltaic Packaging Preprint; M.D. Kempe, G.J. Jorgensen, K.M. Terwilliger, T.J. McMahon, and C.E. Kennedy; Presented at the 2006 IEEE 4th World Conference on Photovoltaic Energy Conversion (WCPEC-4); Waikoloa, Hawaii; May 7-12, 2006.

[6] F. Kadirgan , Electrochemical Nano-Coating Processes in Solar Energy Systems, Hindawi Publishing Corporation Article ID 84891, Pages 1-5

[7] Palz, Wolfgang (2010). Power for the World - The Emergence of Electricity from the Sun. Belgium: Pan Stanford Publishing. p. 6.

[8] K. Zweibel, J. Mason, V. Fthenakis, "A Solar Grand Plan", Scientific American, Jan 2008. CdTe. https://www.corrosionpedia.com/definition/1207/silverInternational Journal of Photoenergy Volume 2006, 